\title{
ESTUDO DA JUSTIÇA UNIVERSAL: A RELAÇÃO ENTRE A ORDEM NATURAL E ORDEM MORAL EM JEAN-JACQUES ROUSSEAU $^{1}$
}

\section{STUDY OF UNIVERSAL JUSTICE: THE RELATION BETWEEN NATURAL ORDER AND MORAL ORDER IN JEAN-JACQUES ROUSSEAU}

Caius Brandão*

Recebido: 09/2016 Aprovado: 05/2017

\begin{abstract}
Resumo: Para aprofundar a compreensão acerca do status ontológico da "justiça universal" no pensamento político e filosófico de Jean-Jacques Rousseau, o artigo busca identificar e descrever os seus atributos mais essenciais. Com este propósito, coloca em questão a sua genealogia e teleologia. Além disso, empreende um esforço para conhecer a sua temporalidade, extensão, bem como seus modos e condições de existência. Por meio de uma análise sistemática dos seus elementos constitutivos, foi possível evidenciar as relações da justiça universal com a ordem natural, no âmbito da filosofia moral do filósofo de Genebra. O texto conclui que a ideia de uma justiça universal compreende um conjunto invariável de princípios, valores, direitos e deveres sagrados a todo ser humano. Contudo, conclui também que a universalidade deste modelo de justiça não é absoluta, e sim relativa, porque a sua exsitência e efetividade dependem de seres sensíveis, livres e racionais, capazes de se darem leis.
\end{abstract}

Palavras-chave: Justiça universal. Ordem natural. Ordem moral. Rousseau.

\begin{abstract}
For an in-depth understanding toward the ontological status of the "universal justice" in the political and philosophical thought of Jean-Jacques Rousseau, the paper seeks to identify and describe its most essential attributes. For this purpose, it calls into question its genealogy and teleology. Furthermore, the paper seeks to bring into light its temporality, extension, as well as its modes and conditions of existence. Through a systematic analysis of its constituent elements, it became clearer the relations between the universal justice with the natural order, in the context of Rousseau's moral philosophy. The article concludes that the idea of a universal justice comprises an invariable set of principles, values, sacred rights and duties of every human being. However, it also concludes that the universality of this model of justice is not absolute, but relative because its existence and effectiveness depends on sensitive, free and rational beings able to give laws to themselves. Keywords: Universal justice. Natural order. Moral order. Rousseau.
\end{abstract}

\section{Introdução}

É certo que se quisermos identificar elementos fundamentais para nos auxiliar a conceber com maior profundidade a ideia da justiça universal na obra de Rousseau, tais como a sua origem, os seus princípios, as suas leis e as suas prováveis finalidades, devemos ter em mente tanto as suas especulações metafísicas sobre a justiça divina, quanto a sua filosofia política. Mas, acima de tudo, devemos nos concentrar no estudo sobre o homem e nas investigações genealógicas da justiça e da moral, no Segundo discurso e, também, no Emílio, onde o Vigário de Sabóia apresenta a teoria da consciência que nos propicia a conhecer com maior profundidade a filosofia moral de Rousseau. Assim, com o

\footnotetext{
* Bacharel e Mestre em Filosofia pela Universidade Federal de Goiás (UFG). Membro da Equipe Editorial da Revista Inquietude (UFG). E-mail: caiusbrandao@gmail.com

Problemata: R. Intern. Fil. V. 8. n. 2 (2017), p. 117-137 ISSN 2236-8612

doi:http://dx.doi.org/10.7443/problemata.v8i2.30709
} 
auxílio principal dessas duas obras, bem como dos trabalhos de alguns estudiosos do pensamento do filósofo, buscaremos descrever aqui alguns elementos essenciais da justiça universal.

Identificamos na Profissão de Fé do Vigário Saboiano duas noções ontologicamente distintas de justiça. Por um lado, temos a justiça divina que pertence ao plano metafísico, incognoscível ao homem. Mas além da justiça de Deus, existe também a justiça universal que, justamente por ser um fruto da moralidade, se dá no âmbito das relações humanas.

Se na Profissão de Fé os sentimentos morais são tratados pelo Vigário Saboiano como objetos metafísicos, no Segundo discurso, ao inseri-los na hipotética história universal da espécie humana, Rousseau identifica o momento mais provável, bem como as condições determinantes para que a moralidade e, consequentemente, a justiça se tornassem necessárias entre os homens. Mesmo que eventualmente o genebrino tenha utilizado a observação de fenômenos para verificar algumas de suas deduções conceituais, o método utilizado no Segundo discurso é essencialmente filosófico. Conforme avalia Robert Derathé:

É então pelo raciocínio que Rousseau elabora sua teoria do homem selvagem, e se, como mostrou Gilbert Chinard, ele leva em consideração observações e fatos contidos nos relatos de viagem, os faz secundariamente e apenas na medida em que nestes ele encontra uma verificação de suas deduções e a confirmação de seu princípio inicial (DERATHÉ, 2009, p. 204-205).

Roger Masters também afirma o caráter essencialmente racional do Segundo discurso e argumenta que nele o estudo da moral, ao contrário da Profissão de Fé,

(...) presumes neither belief in God nor any particular metaphysical explanation of the status of man in the material universe; the Discourse considers the existence of all morality - and, a fortiori, any natural law prescribing man's eternal duties - as an open question requiring rational proof (MASTERS, 1968, p. 111).

Masters segue a influência de Leo Strauss, para quem "o Segundo discurso é a obra mais filosófica de Rousseau. (...) A moral é aí tida, não como uma pressuposição não discutida ou inquestionável, mas como um objeto ou como um problema" (STRAUSS, 2009, p. 225).

Não obstante a importância do Segundo discurso para a compreensão da justiça e da moral, aqui é importante salientar que, no Emílio, especialmente na Profissão de Fé, elas serão tratadas em profundidade na perspectiva da subjetividade humana. Com o auxílio desse texto, tentaremos demonstrar que o filósofo atribui ao indivíduo qualidades inatas e adquiridas que viabilizariam a moralidade em suas ações e a possibilidade da justiça entre os homens. 
A seguir, buscaremos fazer uma descrição da justiça universal, aqui compreendida como um fruto tanto do artifício (a razão), quanto da natureza humana (os sentimentos morais). Para tanto, como fez Rousseau, sempre que possível, colocaremos entre parênteses a análise de dados históricos, bem como as conjeturas que a partir dela seria legítimo estabelecer. Em outras palavras, relegaremos os fatos ao papel secundário de justificação dos princípios estabelecidos pelo filósofo. Assim, procuraremos construir uma cadeia argumentativa a partir do arcabouço principiológico de Rousseau, nos limitando ao recurso do raciocínio crítico e analítico, e nos deixando ser guiados por questões que indagam sobre os elementos essenciais à ideia de uma justiça universal.

\section{O homem capaz de justiça}

Aqui, deixaremos em segundo plano as considerações sobre o percurso histórico realizado pelo "homem selvagem" que forjou o surgimento daquele que é capaz de justiça - o homem do homem. Observaremos primordialmente o indivíduo humano em seu aspecto metafísico. Estabeleceremos como objeto as suas faculdades naturais, essenciais ao desenvolvimento da moral, para, em seguida, relacioná-las ao surgimento do sentimento e da ideia de justiça.

Tomando como referência principal o Segundo discurso, podemos separar em dois grupos distintos as qualidades naturais que constituem a natureza do homem. O primeiro deles inclui os atributos que não necessitam de fatores externos para se desenvolverem, tais como o amor de si e a igualdade. O segundo grupo compreende as qualidades virtuais, isto é, aquelas que mesmo sendo inatas, dependem de ocorrências históricas para tornarem-se plenamente ativas, como é o caso da piedade (que dará lugar aos sentimentos morais ou à consciência), da perfectibilidade, da razão, da sociabilidade e da liberdade. Em outras palavras, buscaremos expor as qualidades ontológicas do homem natural, bem como as sucessivas mudanças que ocorreram em sua natureza, forjando o surgimento do homem civil e elevando-o à condição de ser justo.

Para chegar às faculdades essenciais ao homem natural, Rousseau parte da identificação dos elementos que permanecem ao fim de um processo de generalizações de atributos comuns em cada indivíduo, bem como da subtração daquilo que foi artificialmente adquirido na vida em sociedade, revelando assim o homem tal como ele foi criado pela natureza. Como o próprio filósofo reconhece no Prefácio do Segundo discurso, "não constitui empreendimento trivial separar o que há de original e de artificial na natureza atual do homem" (ROUSSEAU, 1988, p. 32). Assim, a mutabilidade da 
natureza do homem nos coloca diante de um dilema: se a alma humana realmente teria se degenerado a ponto de se tornar irreconhecível, ou se esta mutação teria apenas ocultado as suas faculdades primitivas, e que, mesmo escondida sob os artifícios adquiridos, ela sempre permaneceu idêntica a si mesma. $^{2}$ Essa questão emerge quando Rousseau, na mesma obra, retoma o mito platônico da estátua de Glauco:

Como a estátua de Glauco, que o tempo, o mar e as intempéries tinham desfigurado de tal modo que se assemelhava mais a um animal feroz do que a um deus, a alma humana, alterada no seio da sociedade por milhares de causas sempre renovadas, pela aquisição de uma multidão de conhecimentos e de erros, pelas mudanças que se dão na constituição dos corpos e pelo choque contínuo das paixões, por assim dizer mudou de aparência a ponto de tornar-se quase irreconhecível (ROUSSEAU, 1988, p. 31).

Diante da visão pessimista de que a natureza do homem teria se degenerado definitivamente, e daquela mais otimista que defende que a sua natureza, oculta pelas novas aquisições, sempre permanece inalterada, o que aqui nos importa reconhecer é que, para o filósofo, o atributo de justo, ou até mesmo de injusto, somente poderia ser corretamente utilizado para descrever o indivíduo humano cuja constituição original já tivesse sofrido sucessivas mudanças, a ponto de haver desenvolvido as faculdades que o homem primitivo recebera apenas potencialmente. No Contrato social, Rousseau atribui tais mudanças à passagem que seres humanos teriam feito do estado de natureza para o estado civil. Em suas próprias palavras:

A passagem do estado de natureza ao estado civil produz no homem uma mudança considerável, substituindo em sua conduta o instinto pela justiça e conferindo às suas ações a moralidade que antes lhes faltava. Só então, assumindo a voz do dever o lugar do impulso físico, e o direito o do apetite, o homem, que até então não levara em conta senão a si mesmo, se viu obrigado a agir com base em outros princípios e a consultar sua razão antes de ouvir seus pendores. Conquanto nesse estado se prive de muitas vantagens concedidas pela natureza, ganha outras de igual importância: suas faculdades se exercem e se desenvolvem, suas ideias se alargam, seus sentimentos se enobrecem, toda a sua alma se eleva a tal ponto que, se os abusos dessa nova condição não o degradassem amiúde a uma condição inferior àquela de que saiu, deveria bendizer sem cessar o ditoso instante que dela o arrancou para sempre, transformando-o de um animal estúpido e limitado num ser inteligente, num homem (ROUSSEAU, 1999, p. 25-26).

A todas essas novas aquisições deve-se acrescentar a liberdade moral que é, conforme Rousseau, "a única que torna o homem verdadeiramente senhor de si, porquanto o impulso do mero apetite é escravidão, e a obediência à lei que se prescreveu a si mesmo é liberdade" (ROUSSEAU, 1999, p. 26).

Podemos então deduzir que para ser justo, o homem deve ser minimamente um ser moralmente livre e em relações duradouras com outros 
seres humanos. Acontece que na condição de isolamento, a conduta do homem estaria voltada somente para a sua própria conservação, ditada unicamente pelo instinto. A sua alma seria como um ente absoluto, um todo completo em si mesmo, como um ser que quer nada mais do que a sua própria satisfação. Guiado unicamente pelo amor de si que, de acordo com o filósofo, "é sempre bom e sempre conforme à ordem" (ROUSSEAU, 2004, p. 288), a sua conduta estaria sempre em total acordo com as leis da natureza, mesmo não tendo delas a menor consciência. Mas sem a razão para lhe conferir uma vontade inteligente, o homem seria incapaz de ser dar leis, e a sua conformidade com as leis naturais seria uma "mera escravidão" que em nada se refere à ordem moral. Somente quando uma conduta for consequência de uma vontade livre, poderemos falar em justiça ou injustiça. Logo, seria equivocado imaginar que o homem movido somente pelo amor de si, mas desprovido de razão, tal como a natureza o concebeu, fosse capaz de maldade. Conforme explica Rousseau:

\footnotetext{
Parece, a princípio, que os homens nesse estado de natureza, não havendo entre si qualquer espécie de relação moral ou de deveres comuns, não poderiam ser nem bons nem maus ou possuir vícios e virtudes, a menos que, tomando estas palavras num sentido físico, se considerem como vícios do indivíduo as qualidades capazes de prejudicar sua própria conservação, e virtudes aquelas capazes de em seu favor contribuir, caso em que se poderia chamar de mais virtuosos àqueles que menos resistissem aos impulsos simples da natureza (ROUSSEAU, 1988, p. 55).
}

Então, diante da incapacidade de se conceber os deveres morais e da completa submissão "aos impulsos simples da natureza", não há tampouco a possibilidade de injustiça. Mas, além do amor de si, a bondade natural do homem é fruto de outra faculdade universal e pré-reflexiva, a qual o filósofo define como sendo uma "repugnância inata de ver sofrer seu semelhante" (ROUSSEAU, 1988, p. 57). Trata-se do sentimento de piedade, que nada mais é do que uma transformação do amor de si. A compaixão do homem natural é um sentimento que ocorre quando o sofrimento de seu semelhante obriga aquela mesma vontade que quer o bem de si a se voltar sobre si mesma, num movimento reflexivo de automoderação. Assim, a piedade pode ser então compreendida como uma paixão moderadora do amor de si, cuja função natural seria a conservação da espécie humana. ${ }^{3}$ Nas palavras do filósofo: "Certo, pois, a piedade representa um sentimento natural que, moderando em cada indivíduo a ação do amor de si mesmo, concorre para a conservação mútua da espécie. Ela nos faz, sem reflexão, socorrer aqueles que vemos sofrer" (ROUSSEAU, 1988, p. 58).

O sentimento de piedade, "obscuro e vivo" no homem natural, conforme Rousseau, "ocupa o lugar das leis, dos costumes e da virtude, com a vantagem de ninguém sentir-se tentado a desobedecer à sua doce voz" (ROUSSEAU, 
1988, p. 58). Sem as luzes da razão desenvolvida, a resposta do homem natural ao sentimento da piedade é puramente instintiva e espontânea. Mas, eventualmente, a piedade natural dá lugar à consciência moral, contribuindo com o surgimento das afeições que fortalecem o liame social $e$, consequentemente, da moralidade entre os homens.

$\mathrm{Na}$ concepção de Rousseau, a espécie humana ocupa o topo da hierarquia na ordem geral das coisas naturais: "vejo um animal menos forte do que uns, menos ágil do que outros, mas, em conjunto, organizado de modo mais vantajoso do que todos os demais" (ROSSEAU, 1988, p. 42). Mas, nessa ordem natural em que reina o homem, as desigualdades entre os indivíduos humanos não estão autorizadas em suas relações morais ou políticas. O genebrino admite como naturais somente as desigualdades físicas e aquelas que se referem às "qualidades do espírito e da alma". Nas palavras do filósofo:

\begin{abstract}
Concebo, na espécie humana, dois tipos de desigualdade: uma que chamo de natural ou física, por ser estabelecida pela natureza e que consiste na diferença das idades, da saúde, das forças do corpo e das qualidades do espírito e da alma; a outra, que se pode chamar de desigualdade moral ou política, porque depende de uma espécie de convenção e que é estabelecida ou, pelo menos, autorizada pelo consentimento dos homens. Esta consiste nos vários privilégios de que gozam alguns em prejuízo de outros, como o serem mais ricos, mais poderosos e homenageados do que estes, ou ainda por fazerem-se obedecer por eles (ROUSSEAU, 1988, p. 39).
\end{abstract}

Portanto, a desigualdade do tipo moral ou política, tal como aquela entre o senhor e o escravo, não é estabelecida pela natureza, mas pelas convenções humanas. Já as desigualdades naturais não são muito acentuadas e acabam se anulando. Em vista da pouca importância das desigualdades produzidas pela natureza, Rousseau demonstra no Segundo discurso que é no âmbito do artifício que se dão a origem e os fundamentos das profundas desigualdades morais entre os homens, e que as mesmas são autorizadas somente por convenção e nunca pela própria natureza. Dessa forma, Rousseau é então forçado a reconhecer a igualdade como uma condição que define a constituição natural do homem.

Com o princípio de igualdade, os homens são capazes de estabelecer a "identidade de nossa natureza", particularmente, a qualidade comum que possuímos entre nós de sermos seres sensíveis, o que fundamenta a única forma de sociabilidade natural admitida por Rousseau. ${ }^{4} \mathrm{Na}$ introdução que faz ao Segundo discurso, Rousseau observa que até mesmo os animais, por também possuírem uma natureza sensível, participam do direito natural, obrigando os homens a observarem certos deveres para com eles. Enquanto que na conduta dos animais a natureza opera sozinha, guiando-os exclusivamente pelo instinto para que assim possam se recompor, se defender 
e se reproduzir, na conduta do homem existe um elemento que o distingue das demais criaturas sensíveis: o livre arbítrio. Estando as escolhas dos animais irremediavelmente submetidas aos seus próprios instintos, as bestas são escravas da natureza. O homem, ao contrário, é capaz de se desviar de seus impulsos físicos e se conduzir como agente livre.

Sem os auspícios da razão, os homens então estariam escravizados pelos impulsos do puro apetite, tais como os outros animais. Somente com o auxílio das luzes o homem pôde alcançar a liberdade, conceito axial na filosofia moral de Rousseau, elevando-o à capacidade de fazer escolhas para se desviar ou seguir as regras prescritas pela natureza. ${ }^{5}$

Mesmo que o atributo de agente livre constitua uma diferença específica entre os seres humanos e os demais animais, será a qualidade de ser perfectível a principal característica distintiva do homem. A perfectibilidade é uma faculdade que, com o estímulo de fatores externos, promove novas habilidades definidoras do homem, tais como a razão, a linguagem, a sociabilidade e a liberdade. Graças à perfectibilidade, o homem pôde deixar a condição quase animalesca do estado de natureza e se tornar plenamente humano no estado civil.

Da mesma forma como o dom da perfectibilidade é considerado como o principal responsável tanto pelo surgimento das virtudes quanto dos vícios, ele é também o que possibilitou a ruptura ontológica do ser e do parecer. $\mathrm{Na}$ interpretação de Jean Starobinski, "a ruptura entre o ser e o parecer engendra outros conflitos, como uma série de ecos amplificados: ruptura ente o bem e o mal (entre os bons e os maus), ruptura entre natureza e sociedade, entre o homem e seus deuses, entre o homem e ele próprio" (STAROBINSKI, 2011, p. 13). Conforme Rousseau sugere em sua crítica direcionada à cultura do homem moderno, no Discurso sobre as ciências e as artes: "como seria doce viver entre nós, se a contenção exterior sempre representasse a imagem dos estados do coração" (ROUSSEAU, 1988, p. 139). Antes de o amor de si ser sufocado pelo amor próprio e de a inocência original dar lugar à ideia de consideração, as atitudes dos homens sempre expressavam o que sentia o coração. De acordo com Starobinski,

\footnotetext{
com a reflexão, termina o homem da natureza e começa 'o homem do homem'. A queda nada mais é que a intrusão do orgulho; o equilíbrio do ser sensitivo está rompido; o homem perde o benefício da coincidência inocente e espontânea consigo mesmo. (...) A ruptura entre ser e parecer passa a marcar o triunfo do 'factício', a distância cada vez maior que nos afasta não apenas da natureza exterior, mas de nossa natureza interior (STAROBINSKI, 2011, p. 44).
}

Para alcançar a capacidade de se transformar em agente moral, uma série de mudanças ocorreu na constituição natural do homem, pois as primeiras qualidades essenciais concedidas pela própria natureza são em si 
mesmas insuficientes para dar moralidade às suas ações. Ora, se a justiça universal é uma consequência da ação moral, então o seu surgimento é tributário do pleno desenvolvimento de outros atributos essenciais, até então dormentes na alma humana, tais como a razão e os sentimentos morais ou a consciência.

\title{
Princípio da bondade humana
}

Para Rousseau, a justiça é inseparável da bondade. Neste momento em que nos debruçamos sobre a compreensão da justiça universal, a ligação intrínseca entre esses dois conceitos se torna uma vez mais evidente na filosofia moral do genebrino. No Livro IV do Emílio, o filósofo demonstra a importância dos sentimentos para o surgimento das primeiras noções do bem e do mal, e como os conceitos de justiça e de bondade, antes de serem dados pelo mero entendimento, são qualidades essenciais da alma humana. Em suas próprias palavras:

\begin{abstract}
Entramos finalmente na ordem moral: acabamos de dar um segundo passo de homem. Se este fosse o lugar, tentaria mostrar como dos primeiros movimentos do coração erguem-se as primeiras vozes da consciência, e como nascem as primeiras noções do bem e do mal dos sentimentos de amor e de ódio; mostraria que justiça e bondade não são apenas palavras abstratas, meros seres morais formados pelo entendimento, mas verdadeiras afecções da alma iluminada pela razão (ROUSSEAU, 2004, p. 323-324).
\end{abstract}

Então, de fato, Rousseau atribui menos à razão do que aos sentimentos a nossa capacidade de bondade, e até mesmo de distinguir o justo do injusto. A mesma compreensão é confirmada pelo Vigário Saboiano em sua Profissão de Fé:

\begin{abstract}
Continuando a seguir o meu método, não extraio essas regras dos princípios de uma alta filosofia, mas encontro-as escritas no fundo do coração, escritas pela natureza em caracteres indeléveis. Basta consultar-me sobre o que quero fazer; tudo o que sinto estar bem está bem, tudo o que sinto estar mal está mal. O melhor de todos os casuístas é a consciência, e só quando regateamos com ela recorremos às sutilezas do raciocínio (ROUSSEAU, 2004, p. 404).
\end{abstract}

Assim, as regras "escritas no fundo do coração" do homem pela natureza podem ser acessadas graças àquilo que Rousseau chama de consciência ou de sentimentos morais. Nas palavras do Vigário:

Existe, pois, no fundo das almas um princípio inato de justiça e de virtude a partir do qual, apesar de nossas máximas, julgamos nossas ações e as de outrem como boas ou más, e é a esse princípio que dou o nome de consciência (ROUSSEAU, 2004, p. 
Se os sentimentos morais que nos fazem tender ao bem são constitutivos da natureza humana, então, com o auxílio da razão e da experiência, as ideias de justiça e as noções de bem e de mal podem ser universalizadas. Na Profissão de Fé, o Vigário de Sabóia argumenta:

\footnotetext{
Olha para todas as nações do mundo, percorre todas as histórias. Dentre tantos cultos inumanos e estranhos dentre a prodigiosa diversidade de costumes e de caracteres, encontrarás por toda parte as mesmas ideias de justiça e de honestidade, por toda parte as mesmas noções de bem e de mal (ROUSSEAU, 2004, p. 408).
}

Em suma, "a bondade do homem é o amor de seus semelhantes" (ROUSSEAU, 2004, p. 403) e "o amor dos homens derivado do amor de si é o princípio da justiça humana" (ROUSSEAU, 2004, p. 324). Enfim, podemos concluir com Rousseau que "o primeiro sentimento da justiça" é universal ao gênero humano. O filósofo, pelas palavras do Vigário, atribui à natureza humana, por meio da consciência, a qualidade de amar o bem e odiar o mal:

\begin{abstract}
Para tanto, só é preciso fazer com que distingas nossas ideias adquiridas e nossos sentimentos naturais, pois sentimos antes de conhecer, e, como não aprendemos a querer o nosso bem e a evitar o nosso mal, mas recebemos essa vontade da natureza, também o amor do bom e o ódio do mau são-nos tão naturais quanto o amor de nós mesmos. Os atos da consciência não são juízos, mas sentimentos. Embora todas as nossas ideias nos venham de fora, os sentimentos que as apreciam estão dentro de nós e é só por eles que conhecemos a conveniência ou inconveniência que existe entre nós e as coisas que devemos respeitar ou evitar (ROUSSEAU, 2004, p. 410).
\end{abstract}

Devemos então reconhecer a importância da consciência ou do princípio da justiça derivado do amor de si, ao mesmo tempo em que devemos também considerar fundamental o papel realizado pela razão para a existência da justiça universal. Conforme vimos anteriormente, no Contrato social, Rousseau afirma categoricamente que a justiça universal emana somente da razão. Também na Profissão de Fé do Vigário Saboiano nós podemos identificar este mesmo entendimento: "o homem não tem um conhecimento inato do bem; mas, assim que a sua razão faz com que o conheça, sua consciência leva-o a amá-lo: é este sentimento que é inato" (ROUSSEAU, 2004, p. 411). Mais adiante, o Vigário indaga: "Não me deu ele [Deus] a consciência para amar o bem, a razão para conhecê-lo, a liberdade para escolhê-lo? Se ajo mal, não tenho desculpas; faço-o porque o quero" (ROUSSEAU, 2004, p. 417). Assim, além da consciência e da razão, a liberdade da vontade é outro elemento sem o qual não haveria a possibilidade de uma justiça universal. Isto porque para que haja justiça é necessária também uma ação 'boa', isto é, uma ação livre e 
126

conforme a ordem, independentemente desta ordem ser natural ou convencionada. Disto decorre que não podemos circunscrever a justiça universal ao plano metafísico do amor de si e, consequentemente, tampouco à natureza humana. Se a justiça universal emana da razão, então ela é também um fruto do artifício. Daí a importância de descrevermos o homem capaz de justiça não somente como um ser sensível, mas também racional e livre, que age de acordo com as leis que ele é capaz de se dar. Nas palavras do Vigário Saboiano,

Qual é, então, a causa que determina sua vontade? É o seu juízo. E qual é a causa que determina seu juízo? É sua faculdade inteligente, é sua potência de julgar; a sua determinante está nele mesmo. Além disso, nada mais entendo (ROUSSEAU, 2004, p. 395).

Assim, por mais que exista em seu bojo um princípio de bondade (os sentimentos morais), a justiça universal é também um artefato da razão e da livre vontade humana. Desta forma, não existe justiça na natureza, mesmo que nela não possa necessariamente haver injustiça. Desta maneira, devemos concluir que a bondade natural, iluminada pelas luzes da razão, deve ser considerada como um princípio da justiça universal.

\section{Princípios, leis e desordem}

Antes de anunciar o seu terceiro artigo de fé - de que o homem é livre em suas ações -, o Vigário Saboiano declara que o princípio de toda ação está na vontade de um ser livre. Ora, se o homem é um ser de natureza excelente, dotado de faculdades que o colocam em condição de fazer escolhas, e ainda se a justiça decorre de uma ação conforme a ordem, então, é forçosa a conclusão de que a liberdade da vontade é um princípio da justiça universal. Mas se, por um lado, a metafísica do Vigário Saboiano não nos oferece um terreno sólido o suficiente para fundamentar a liberdade do homem, por outro, encontramos no Segundo discurso a demonstração filosófica de que o mal moral não é obra da natureza, mas da sociedade que forjou no homem, livre por natureza, uma racionalidade a serviço do amor próprio, gerando, como consequência, a injustiça e a desordem. Foi justamente a supressão da voz da natureza que fala aos corações dos homens, supressão motivada pelas necessidades artificiais geradas por vícios adquiridos em sociedade, que possibilitou a degeneração da espécie humana. Assim, ao abusar de sua liberdade natural, os homens se tornam escravos de seus vícios. Por outro lado, é justamente o encontro entre a natureza e o artifício - entre a consciência e a razão - que faz do homem um ser de vontade livre e capaz de 
agir moralmente. Em Jean-Jacques Rousseau and the 'well-ordered society', ao discutir sobre as imagens de ordem entre o natural e o artificial, Maurizio Viroli aborda a complexidade do relacionamento entre estas duas dimensões (natureza e razão) no que tange ao conhecimento e à moralidade. Viroli lembra que "So long as man is not capable of making comparisons and judgments on the interconnection between things and between cause and effect, he will not be capable of leading a moral life either." Mais a frente, Viroli continua: "Rousseau' ethic assumes that there is an artificial condition (the activity of making comparisons which is in the domain of reason) and a natural feeling (conscience)" (VIROLI, 1988, p. 22). Sobre o desencadeamento de uma ação moral, Roger Masters esclarece que, conforme Rousseau, "Although reason is the necessary prerequisite for the existence of the conscience, without an appeal to the conscience - or, more generally, to the sentiments - reason itself is incapable of moving men to action" (MASTERS, 1968, p. 75-76). Neste sentido, a justiça é um ato virtuoso de liberdade e uma expressão inteligente do amor de si.

Paradoxalmente, enquanto a consciência nos faz tender naturalmente à justiça e fundamenta os preceitos morais, tais preceitos sequer seriam reconhecidos sem os auspícios da razão. Isso significa que a boa vontade de agir com justiça - isto é, conforme a ordem moral - tem como princípios tanto a qualidade sensitiva quanto a capacidade racional do ser humano. A natureza nos oferece o impulso, mas somente com o auxílio da razão seríamos capazes, por meio da justiça universal, de estabelecer entre nós a ordem moral. Devemos então prosseguir colocando novamente em evidência as fontes e a natureza deste tipo de ordem.

Para Rousseau, a ordem natural compreende leis físicas invioláveis para todos os seres materiais, mas também preceitos morais que podem ou não ser obedecidos, na medida em que eles são prescritos pela natureza aos seres sensitivos e inteligentes, cuja vontade é livre para aquiescer ou resistir. De acordo com Roger Masters, "thus there should be no question concerning the precise meaning of the term natural law according to Rousseau: because it refers to a law which nature prescribes to man as a free agent capable of reasoning, the term must be distinguished from the notion of 'law of nature' that are physically necessary" (MASTERS, 1968, p. 79-80). Nesta perspectiva, somos forçados a concluir que os preceitos morais são naturais e que a ordem moral é, antes de tudo, uma obra da divindade. ${ }^{6}$ Em outras palavras, teríamos que admitir a existência de uma ordem moral metafísica, portanto, independente da vontade e da ação do homem. Maurizio Viroli confirma essa mesma interpretação quando afirma: "Moral order is not a result of social conventions. It is independent of the moral judgments of individuals since it has been established by God" (VIROLI, 1988, p. 22). 
Já no domínio da ética, isto é, do estudo de uma ordem moral entre os homens, para Rousseau, a razão de ser dos preceitos morais está na própria natureza do indivíduo que o inspira a buscar o bem de si. O real fundamento para o indivíduo agir moralmente não é a razão, que lhe mostra somente desvantagens em ser justo, mas as "afecções da alma iluminada pela razão, que não são mais que um progresso ordenado de nossas afecções primitivas." (ROUSSEAU, 2004, p. 323-324) Diz o filósofo:

Mas, quando a força de uma alma expansiva identifica-me com meu semelhante e sinto-me, por assim dizer, nele, é para não sofrer que não quero que ele sofra; interesso-me por ele por amor de mim e a razão do preceito está na própria natureza que me inspira o desejo de meu bem-estar em qualquer lugar em que me sinta existir. Daí, concluo que não é verdade que os preceitos da lei natural estejam baseados unicamente na razão, pois eles têm uma base mais sólida e mais segura. O amor dos homens derivado do amor de si é o princípio da justiça humana (ROUSSEAU, 2004, p. 324).

Assim, na genealogia da moral, encontramos a consciência - elemento universal aos homens que serve de fundamento ao reconhecimento racional das regras do direito natural. Aqui, vale lembrar o que disse Rousseau, no Livro IV do Emílio:

Pela mera razão, independentemente da consciência, não podemos estabelecer nenhuma lei natural; e que todo o direito da natureza não passa de uma quimera se não é fundamentado numa necessidade natural ao coração humano (ROUSSEAU, 2004, p. 324).

Apesar de a consciência ser o guia mais seguro para homem agir moralmente, conforme o Vigário Saboiano, "não basta que esse guia exista, é preciso saber reconhecê-lo e segui-lo" (ROUSSEAU, 2004, p. 412). Logo, para que a justiça universal possa se realizar entre os homens, além de serem acessadas pela consciência, as leis morais devem ser racionalmente reconhecidas e livremente obedecidas.

Temos então que, sob o ponto de vista metafísico, as leis relativas à ordem moral são eternas e absolutas, mas no âmbito da ética, elas só se constituem enquanto tais quando os homens passam a conviver entre si e desenvolvem a sua faculdade racional. Em outras palavras, a existência e a efetividade das leis morais, nas relações interpessoais, dependem de operações realizadas pela consciência, pela razão e pela liberdade dos homens. .

Para Maurizio Viroli, a ética e a teoria do conhecimento de Rousseau ${ }^{7}$ pressupõem uma ordem moral objetiva, bem como a existência de uma verdade objetiva. Vejamos, com as suas próprias palavras, como Viroli compreende a relação entre a teoria do conhecimento e a ética do pensador de 
Genebra, no que concerne o reconhecimento racional de uma ordem moral na natureza:

\begin{abstract}
Though human knowledge is in part the work of man, it comes into contact with an independent reality which is intrinsically rational in that it is a product of the divine intelligence. Truth and rational knowledge are not, in Rousseau's view, human conventions. They consist, rather, in the recognition of an order and a reality which already exist in things. In a similar way Rousseau's ethic, while adopting wholeheartedly the idea of free moral choice, does not for this reason argue for any reshaping of the moral order through human artifice, for it does not owe its existence to human conventions, but to God, and men cannot and should not change it" (VIROLI, 1988, p. 23).
\end{abstract}

Ainda de acordo com Viroli: "With regard to knowledge, and equally with regard to ethics and politics, man is not just a natural and passive being, he is also active: the ideas of relation and order are not merely imposed upon him, he constructs them himself' (VIROLI, 1988, p. 19). Seguindo esta chave interpretativa, temos então que as leis morais são verdades eternas que os homens podem construir racionalmente, com base nos sentimentos morais.

Ao contestar Charles Edwyn Vaughan acerca da suposta negação de Rousseau da ideia de lei natural, Robert Derathé defende a existência de dois tipos de direito natural, no pensamento do filósofo genebrino: "um, secundum motus sensualitatis, é o 'direito natural propriamente dito', aquele que convém ao estado de natureza, o outro, secundum motus rationis ou 'direito natural raciocinado, só aparece após o estabelecimento das sociedades civis" (DERATHÉ, 2009, p. 250). Em seguida, Derathé conclui: "Rousseau é levado a fazer uma distinção entre o direito natural primitivo, anterior à razão, e o direito natural restabelecido pela razão" (DERATHÉ, 2009, p. 252). Sobre essa questão que tangencia o debate sobre o jusnaturalismo em Rousseau, Roger Masters nos parece fazer uma importante contribuição quando ele esclarece que, enquanto no Segundo discurso o filósofo critica a escola tradicional do direito natural e, no Contrato social, ele defende que o direito político é independente da natureza, no Emílio, Rousseau fala de uma "lei natural" como elemento de ligação entre os homens vivendo em sociedade. Para Masters, devemos nos ater ao duplo objetivo de Rousseau que, por um lado, tenta reformular os ensinamentos tradicionais do direito natural ao introduzir a consciência, ou os sentimentos, como fonte de aprendizado das obrigações morais, mas, por outro, restringe radicalmente a importância da lei natural, na medida em que ela é impotente para o homem, no estado de natureza, e irrelevante para o cidadão. Em suas próprias palavras: "This double objective must be constantly borne in mind, because Rousseau uses his reformulated natural law as a possible basis for individual virtue in the case where civic virtue is impossible, just as he uses civic morality as a solution for the impotence of 
natural law" (MASTERS, 1968, p. 77).

Para Rousseau, não resta dúvida sobre a autoria divina da ordem moral. Todavia, para que a justiça universal se realize, antes, o homem deve reconhecer ou descobrir as leis naturais nas coisas mesmas, a partir do estudo da própria natureza humana. Na introdução ao Segundo discurso, o filósofo afirma:

Enquanto, porém, não conhecermos o homem natural, em vão desejaremos determinar a lei que ele recebeu ou aquela que melhor convém à sua constituição. Quanto podemos apreender bem claramente sobre o objeto dessa lei é que não somente é preciso, para ser lei, que a vontade daquele a que obriga possa submeter-se a ela com conhecimento, como, também, para ser natural, é preciso que se exprima imediatamente pela voz da natureza. (ROUSSEAU, 1988, p. 34)

Assim, guiado por sua consciência e iluminado pela razão, o homem do homem pode apreender as leis naturais e se colocar livremente na ordem moral. Em outras palavras, é o próprio indivíduo quem, num movimento reflexivo, se põe em relação a si mesmo ao se dar uma lei, cuja validade ele pode atribuir um valor absoluto, portanto, anterior a qualquer convenção humana. A despeito de ser Deus indubitavelmente o autor das leis morais, o indivíduo legisla para si mesmo quando pauta a sua conduta com o outro conforme a ordem moral que ele próprio reconhece como natural. Neste sentido, podemos considerá-lo como um legislador de si mesmo. Logo, é sob o ponto de vista estritamente humano que as leis morais da justiça universal emanam da reta razão e encontram o seu fundamento na natureza humana, isto é, na consciência.

O que esteve em jogo até aqui é o reconhecimento de duas fontes distintas da bondade e, consequentemente, da justiça: o amor de Deus à ordem e o amor de $\mathrm{si}^{8}{ }^{8}$ Consequentemente, conforme distintos modelos de justiça, nós podemos constatar a existência de dois legisladores: Deus e o indivíduo humano. Em suma, Deus é o princípio de toda justiça, mas se abandonamos a metafísica para considerarmos unicamente a ética, temos que as leis morais relativas à justiça universal são artefatos edificados pela racionalidade do indivíduo socializado, com fundamento em sua consciência.

De acordo com o genebrino, as leis naturais da ordem moral são regras gerais que não admitem exceção para ninguém. Se os seres humanos compartilham de uma mesma inclinação natural para a benevolência, em outras palavras, se os sentimentos morais são universais, somos então obrigados a concluir que a igualdade natural é um princípio constitutivo daquilo que fundamenta as leis morais. Neste sentido, a igualdade se refere a uma determinada constituição natural do homem que o pré-dispõe à justiça universal. Contudo, essa disposição natural, apesar de universal, não parece ser suficiente para a manutenção da ordem moral. Conforme observa o Vigário 
de Sabóia:

\begin{abstract}
Mas, quando, para depois conhecer meu lugar individual em minha espécie, considero as diversas posições sociais e os homens que as ocupam, que acontece comigo? Que espetáculo! Onde está a ordem que observei? O quadro da natureza só me oferecia harmonia e proporções, o do gênero humano só me oferece confusão e desordem! O concerto reina entre os elementos e os homens estão no caos! Ó sabedoria, onde estão tuas leis? (ROUSSEAU, 2004, p. 392)
\end{abstract}

Este quadro de confusão e desordem é cuidadosamente estudado pelo filósofo, sob diferentes perspectivas e metodologias, no Primeiro e no Segundo discurso. Mas ambos levam à conclusão de que a sociedade civil corrompeu a alma do homem e promoveu a degeneração da espécie. Já no Emílio, Rousseau demonstra que até mesmo o indivíduo da sociedade civil poderá seguir o difícil caminho da virtude, justamente por possuir uma constituição natural que ora o aproxima da justiça e do bem moral, e ora o arrasta para o império das paixões. Talvez essa questão seja mais bem apresentada nas palavras do Vigário:

\footnotetext{
Por que está minha alma submetida aos meus sentidos e acorrentada a este corpo que a subjuga e incomoda? Não sei; (...) Se o espírito do homem tivesse permanecido livre e puro, que mérito haveria em amar e seguir a ordem que ele veria estabelecer e não teria nenhum interesse em perturbar? Seria feliz, é verdade, mas faltaria à sua felicidade o grau mais sublime, a glória da virtude e o bom testemunho de si mesmo; seria apenas como os anjos, e sem dúvida o homem virtuoso será mais do que eles (ROUSSEAU, 2004, p. 414-415).
}

A palavra virtude - conforme assinala Roger Masters por meio de uma citação do Discours sur la Vertu du Héros, de Rousseau - vem da palavra força, pois a força é a base de toda virtude. O homem virtuoso é aquele que sabe como dominar suas paixões e segue a sua razão e a sua consciência. Dessa forma, ele realiza o seu dever e, assim, se mantém na ordem (MASTERS, 1968). Em contrapartida, a sua felicidade alcança o grau mais sublime com o bom testemunho de si mesmo, que é a recompensa imediata da justiça. Inversamente, para o indivíduo cuja consciência se encontra plenamente desenvolvida, o remorso será a consequência necessária da imoralidade. Para ser eficaz, a moralidade pessoal deve contar com uma sanção interna que obrigue o indivíduo, já que o seu interesse próprio poderia levá-lo a ignorar as suas obrigações naturais. Na ausência de uma sanção natural, qualquer regra moral seria meramente um desejo que o mau pode violar em prejuízo do bom (MASTERS, 1968). Aqui é importante salientar que o indivíduo legislador se torna agora juiz de si mesmo, e estabelece internamente um sistema de recompensas e castigos, conforme o bom ou o mau testemunho que faz de si. O problema, contudo, é que além destas possíveis recompensas 
e castigos aplicados subjetivamente, a natureza não impõe nenhum outro tipo de sanção aos maus. Conforme o próprio Rousseau reconhece:

O mal que os maus nos fazem nos leva a esquecer o mal que fazem a si próprios. Perdoaríamos mais facilmente seus vícios se pudéssemos saber o quanto o seu próprio coração os pune por eles. Sentimos a ofensa e não vemos o castigo; as vantagens são visíveis, o sofrimento é interior (ROUSSEAU, 2004, p. 338).

Em consequência da falta de uma sanção natural mais explícita contra o desrespeito aos preceitos morais, o indivíduo reconhece somente desvantagens em seguir o caminho virtuoso da justiça universal, sem nenhuma garantia de que os outros farão o mesmo em relação a ele. Com esse argumento, Rousseau conclui que somente o sentimento, em vez da razão, poderá oferecer os verdadeiros fundamentos da ação moral, como podemos observar nesta passagem do Livro IV do Emílio:

\begin{abstract}
O próprio preceito de agir para com os outros como queremos que ajam para conosco só tem verdadeiro fundamento a consciência e o sentimento, pois onde está a razão precisar de agir, sendo eu, como se eu fosse outro, sobretudo quando estou moralmente certo de nunca me encontrar no mesmo caso? $\mathrm{E}$ quem me garantirá que, seguindo com toda fidelidade essa máxima, conseguirei que a sigam igualmente comigo? O mau tira vantagem da probidade do justo e de sua própria injustiça; é muito cômodo que todos sejam justos, exceto ele. Digam o que disserem, esse acordo não é vantajoso para as pessoas de bem (ROUSSEAU, 2004, p. 324).
\end{abstract}

Em seguida, no Contrato social, Rousseau apresenta a justiça universal como um tipo de justiça ineficaz. Para o pensador, em virtude das ausências de reciprocidade entre os homens e de sanção natural, a justiça universal não produz o efeito desejado, mas, pelo contrário, seria capaz de produzir "o bem do mau e o mal do justo". Assim, diante da incognoscibilidade da justiça divina e da ineficácia da justiça universal, o filósofo idealiza uma organização política e social que possa "unir os direitos aos deveres e conduzir a justiça a seu fim" (ROUSSEAU, 1999, p. 46).

Rousseau reconhece então, no âmbito da justiça universal, a falha do princípio de reciprocidade causada pela falta de sanção natural, o que inviabiliza a realização dos desígnios desse modelo de justiça. Na opinião de Roger Masters, isso aponta para a fragilidade ou, em suas palavras, para a "impotência da lei natural" De acordo com Masters, a partir da perspectiva da análise que Rousseau faz da natureza humana, a máxima fundamental da moralidade pessoal - agir para com os outros como queremos que ajam para conosco - pressupõe uma racionalidade que a torna inacessível para a grande maioria dos homens. Na concepção do comentador, Rousseau promoveu a reformulação da lei natural em uma religião natural, baseada na consciência. Mesmo que esta reformulação negue a primazia da razão, ela permanece 
acessível somente para aqueles que podem raciocinar de forma apropriada.

\begin{abstract}
Since the moral teaching of the Savoyard Vicar is impotent without 'good faith', and good faith is ineffective without Socratic wisdom, the natural law which truly establishes the golden rule, although founded on natural sentiment, is only accepted by those who reason in the manner of Socrates or Jesus" (MASTERS, 1968, p. 85).
\end{abstract}

Então, ainda conforme Masters, em virtude da impotência da lei natural, Rousseau viu-se forçado a basear a justiça em fundamentos mais sólidos, isto é, na sociedade política. Masters, entretanto, reconhece que Rousseau nunca tenha negado a existência de outro possível fundamento para a justiça, mas somente que tal alternativa - isto é, a lei natural - seja impotente para garantila na sociedade. Também na compreensão de Maurizio Viroli, Rousseau confirma a validade da lei natural, mas questiona a sua efetividade:

\begin{abstract}
For Rousseau, the problem of political institutions and of government arises precisely because he adopts as his premise the view that men do not follow the precepts of justice. If they did so we should have no need of governments or law. He does not deny the validity of natural law but only its effectiveness, and especially he does not accept that it is sufficient to provide the basis for social order (VIROLI, 1988, p. 124).
\end{abstract}

\title{
Desígnios
}

No âmbito das relações humanas, devido à falta de aceitação recíproca da ordem moral, as leis da justiça universal tornam-se vãs e são incapazes de unir os direitos aos deveres que a própria natureza prescreve. Como vimos anteriormente, para a maioria dos homens em sociedade, quando não há expectativa de reciprocidade, a razão não oferece ao indivíduo motivos para agir com os outros como quer que ajam com ele. A consequente desordem social representa uma negação da ordem moral, quando fica estabelecida a inviabilidade da justiça universal.

Para Rousseau, a questão sobre a ordem e a justiça emerge como um problema cuja solução não pode ser encontrada na natureza ${ }^{9}$. Se os desígnios da justiça universal apontam para a manutenção da ordem moral e a preservação da espécie, devemos concluir que tais propósitos permanecerão inalcançáveis até que os homens estabeleçam um modelo de organização social e política que preserve o princípio de reciprocidade e una os direitos aos deveres.

\section{Considerações finais}


A constituição natural do homem é perfectível. O indivíduo surge das mãos da natureza isolado de seus semelhantes, mas em completa harmonia e equilíbrio com a ordem natural. Submetido pelas leis da natureza que ele desconhece e obedece por mero impulso instintivo, o homem natural não concebe a justiça, tampouco dela necessita. Somente no convívio com os seus semelhantes, o homem adquire as faculdades naturais que até então existiam apenas em potência. As necessidades causadas por sua nova condição impulsionaram o desenvolvimento da razão, da linguagem, da identidade pessoal, da consciência, da liberdade e, enfim, da sociabilidade. Assim, o homem selvagem dá lugar ao homem do homem que nasce das mãos da sociedade. Sob o ponto de vista da justiça, é na medida em que ela se torna necessária que o indivíduo desenvolve os novos atributos que dão moralidade às suas ações. Em outras palavras, a razão, a consciência e a liberdade tornam o indivíduo capaz de se dar leis e de alcançar a virtude moral ao obedecê-las livremente.

Para Rousseau, a bondade é inseparável da justiça, cujo princípio é o amor dos homens por seus semelhantes. Este sentimento tem como origem o amor de si, fonte de todas as paixões. Mas somente quando iluminada pelas luzes da razão, a bondade natural deve ser considerada como um princípio da justiça universal. A liberdade é outro atributo fundamental, sem o qual não poderia haver justiça. Ademais, a generalidade das suas leis estabelece a igualdade como outra qualidade fundamental deste modelo de justiça. No pensamento do genebrino, as leis morais mais básicas (como amar o semelhante e guardar a palavra dada) são prescritas por Deus. Com base na consciência, os homens podem reconhecer racionalmente tais preceitos, e agir moralmente. Todavia, como não existe uma sanção natural suficiente para sustentar o princípio de reciprocidade, a leis da justiça universal (os preceitos morais) perdem a razão de ser, e a consequência é a desordem social. Para responder a este problema axial da justiça universal, Rousseau não busca modelos na natureza e propõe solucioná-lo no campo da política.

A manutenção da ordem moral e a preservação da espécie humana são os desígnios da justiça universal que permanecerão inalcançáveis até que os homens estabeleçam um modelo de organização social e política que preserve o princípio de reciprocidade e una os direitos aos deveres.

Em suma, a justiça universal representa um modelo no qual as funções de legislador, juiz e autoridade (que recompensa os bons e pune os faltosos) são realizadas pelo próprio indivíduo humano que governa a si mesmo de forma soberana. Mas em virtude da ausência do princípio de reciprocidade, a justiça universal, por si mesma, é incapaz de promover manutenção da ordem moral e a preservação da espécie. Desta forma, fica estabelecida a necessidade incontornável da organização social e política. 
Entretanto, a conclusão de que a justiça universal é um produto da arte humana pode sugerir a seguinte dificuldade: se, para Rousseau, foi a divindade quem criou a ordem natural e se as leis dessa ordem compreendem além das leis físicas, também as leis morais, então, Deus não deveria ser considerado como a fonte primeira da justiça universal? Sob o ponto de vista da metafísica, a leis morais são normas eternas e imutáveis porque são sim frutos da vontade divina. Contudo, Deus criou as leis morais, mas não o obrigou o homem a concebê-las, tampouco a segui-las. A providência não interfere nas ações dos seres sensíveis e inteligentes, já que a eles foi concedida a liberdade para obedecer ou resistir às leis morais. No estudo da justiça universal, o indivíduo humano surge dotado de razão, de sentimento e de liberdade, e com a responsabilidade de desempenhar, em relação a si mesmo, as funções de legislador, juiz e autoridade. Acontece que, para o filósofo, se essa justiça deve existir, antes é necessário que as leis morais sejam apreendidas ou descobertas pelo indivíduo por meio do entendimento e com base no sentimento natural (a consciência). Em seguida, ele deve querer se colocar livremente na ordem moral. Isso significa que é preciso que o indivíduo se ordene, ou melhor, que ele ordene as suas ações conforme aquelas normas morais apreendidas da natureza. Portanto, a ação moral depende de um ato de vontade livre. A justiça universal nada mais é do que o efeito desse ato de vontade, isto é, ela se constitui a partir da vontade individual de se dar regras pelas quais o valor do justo ou do injusto poderá ser atribuído a uma ação. Em outras palavras, a 'justiça universal' pode ser deduzida das condutas dos indivíduos que se conformam livremente com as normas morais (a justiça é a ação do justo). Rousseau concebe esse modelo de justiça como um artefato da razão, justamente porque essa justiça é o efeito de uma ação racional. Roger Masters corrobora essa interpretação quando ele descreve a justiça como uma "invenção humana". Ainda conforme o comentador, a resposta de Rousseau à crítica de Diderot foi justamente o entendimento de que, no âmbito da ética, a lei natural é "unnatural" (MASTERS, 1968, p. 265).

\section{Bibliografia}

DERATHÉ, R. Jean-Jacques Rousseau e a ciência política de seu tempo. Trad. de

Natália Maruyama. São Paulo: Editora Barcarolla; Discurso Editorial, 2009.

MASTERS, R. The political philosophy of Rousseau, New Jersey: Princeton, 1968. 
ROUSSEAU, J.-J. Discurso sobre a origem e os fundamentos da desigualdade entre os homens. Trad. de Lourdes Santos Machado. São Paulo: Nova Cultural, 1988. (Coleção Os Pensadores)

O contrato social ou princípios do direito político. Trad. de Antonio de Pádua Danesi. São Paulo: Martins Fontes, 1999.

Discurso sobre as ciências e as artes. Trad. de Lourdes Santos Machado. São Paulo: Nova Cultural, 2000.

Escritos sobre a religião e a moral. In: Clássicos da Filosofia: Cadernos de Tradução n. 2. Trad. de Adalberto L. Vicente e Ana Luiza S. Camarani. Organização e apresentação de José Oscar de Almeida Marques. São Paulo: IFCH/UNICAMP, 2002.

Emílio ou da educação. Trad. de Roberto Leal Ferreira. São Paulo: Martins Fontes, 2004.

STAROBINSKI, J. Jean-Jacques Rousseau: a transparência e o obstáculo. Trad. de Maria Lúcia Machado. São Paulo: Companhia das Letras, 2011.

STRAUSS, L. Direito natural e história. Trad. de Miguel Morgado. Lisboa: Edições 70, 2009.

VIROLI, M. Jean-Jacques Rousseau and the 'well-ordered society'. Cambridge: Cambridge University Press, 1988.

\footnotetext{
${ }^{1}$ Este artigo é um resultado parcial do projeto de pesquisa de mestrado, Estudo das ideias de justiça no pensamento político-filosófico de Jean-Jacques Rousseau, realizado entre 2013 e 2015, no Programa de Pós-Graduação em Filosofia, da Universidade Federal de Goiás, UFG (Brasil).

${ }^{2}$ Ao levantar este problema em Jean-Jacques Rousseau: a transparência e o obstáculo, Jean Starobinski afirma que o genebrino teria oferecido duas respostas contraditórias: "A primeira, afirma que a alma humana degenerou, que se desfigurou, que sofreu uma alteração quase total, para jamais reencontrar sua beleza primeira. A segunda versão, em lugar de uma deformação, evoca uma espécie de encobrimento: a natureza primitiva persiste, mas oculta, cercada de véus superpostos, sepultada sob os artifícios e, no entanto sempre intacta." $\mathrm{Na}$ visão do intérprete, Rousseau "sustenta ambas, alternadamente, e por vezes mesmo simultaneamente. Diz-nos que o homem destruiu de modo irremediável sua identidade natural, mas proclama também que a alma original, sendo indestrutível, permanece para sempre idêntica a si mesma sob as manifestações externas que a mascaram" (STAROBINSKI, 2011, p. 27-29).

${ }^{3}$ No Capítulo VI - A Crise do Direito Natural Moderno - de sua obra Direito natural e história, Leo Strauss afirma que o resultado do estudo do homem realizado por Rousseau pode ser resumido na sua declaração de que o homem é bom por natureza. Ainda de acordo com Strauss, "Rousseau sugere que o homem natural é compassivo: o gênero humano não poderia ter sobrevivido ao período anterior à existência de restrições convencionais se os impulsos poderosos do instinto da preservação de si não
} 
tivessem sido mitigados pela compaixão. Rousseau parece pressupor que o desejo instintivo da preservação da espécie se divide em desejo de procriação e em compaixão. A compaixão é a paixão de onde decorrem todas as virtudes sociais. Conclui que o homem é por natureza bom porque é por natureza conduzido pelo amor de si e pela compaixão, e está desprovido de vaidade ou orgulho" (STRAUSS, 2009, p. 230).

Para Derathé, "a única forma de sociabilidade que Rousseau admite ou, antes, a única que lhe parece natural é aquela que tem seu fundamento na identidade de nossa natureza sensível" (DERATHÉ, 2009, p. 227). Ainda de acordo com Derathé, "a sociabilidade, segundo Rousseau, é um sentimento inato, assim como a razão é uma faculdade inata. Mas uma e outra só existem 'em potência' no homem natural, pois seu desenvolvimento está ligado a condições que só se encontram reunidas no meio social" (DERATHÉ, 2009, p. 225).

5 Seguindo esta mesma chave interpretativa, o artigo de Renato Moscateli, A liberdade como conceito metafísico e jurídico em Rousseau, aprofunda a análise dessa questão para propor que "a liberdade somente se torna possível com a saída do estado de natureza." De acordo com Moscateli, "o surgimento da consciência e da racionalidade é indispensável para que o homem consiga desenvolver suas faculdades virtuais e seja capaz de criar para si padrões de comportamento diferentes do instinto natural, um processo que ocorre graças à vida em sociedade." Todavia, o próprio autor reconhece que Rousseau "realmente se refere a uma liberdade natural". Em seguida, propõe que seja "indispensável perceber que a expressão 'liberdade natural' não é um simples sinônimo de 'liberdade do homem natural', por mais que se pareça estar frente a coisas iguais" (MOSCATELI, 2008, p. 59 e 72). Neste sentido, a compreensão do termo "liberdade natural" no Segundo discurso deve ser feita sob o ponto de vista jurídico, isto é, a completa ausência de leis positivas no estado de natureza. Já que o conceito de liberdade será identificado como um dos elementos essenciais da justiça universal, nós voltaremos a tratar sobre este tema posteriormente.

${ }^{6}$ Aqui, naturalmente, não estamos nos referindo à totalidade das regras morais, mas aos preceitos mais simples que fundamentam a moralidade como um todo. Tais deveres sagrados incluem a obrigação altruísta de amor ao próximo e o cumprimento das promessas, isto é, a sacralidade da palavra dada. Neste sentido, eles possuem um status ontológico equivalente às leis invocadas por Antígona, as quais, mesmo se não forem escritas pelos homens, são irrevogáveis, isto é, são preceitos universais, absolutos e anteriores a qualquer convenção.

7 Viroli reconhece que Rousseau não desenvolveu uma sistemática teoria do conhecimento. Isso, contudo, afirma o intérprete, não quer dizer que o genebrino não tenha as suas próprias opiniões acerca do conhecimento humano e reconhece uma "grande influência" das mesmas sobre a sua abordagem da filosofia política. Ao analisar as notas feitas por Rousseau em De l'esprit, de Helvétius, Viroli salienta que conforme a teoria rousseauísta, os seres humanos possuem dois princípios, a saber: um passivo, que se refere às impressões que objetos exteriores causam em nossos sentidos; e um ativo, que é a nossa capacidade de fazer comparações ou estabelecer relações entre diferentes objetos apreendidos pelos sentidos. Vejamos como Viroli trata estes dois princípios descritos pelo filósofo: "Rousseau's idea of human knowledge is thus a form of dualism: it is based on the notion that the act of cognition has two components, one active or artificial, and the other passive or natural. Equally, his moral doctrine is also dualist. The very existence of the moral problem depends on the ability to intuit the ideas of connection and relation. Connections and relations are established, or discovered, by men, thanks to their faculty of judgment and the ability to make comparisons. The active nature of man, which finds its expression in the ability to understand and define order, is one of the prerequisites for Rousseau's ethics" (VIROLI, 1988, p. 20).

${ }^{8}$ Em sua Profissão de Fé, o Vigário Saboiano conclui: "A justiça é inseparável da bondade; ora, a bondade é o efeito necessário de uma potência sem limite e do amor de si, essencial a todo ser que sente" (ROUSSEAU, 2004, p. 398).

9 De acordo com Maurizio Viroli, no pensamento de Rousseau, a solução possível para o problema da ordem e da justiça não é dada pela natureza, tampouco pela providência (VIROLI, 1988). Nesta questão, podemos identificar uma convergência entre as leituras de Masters e Viroli, que enxergam na ordem política proposta pelo autor do Contrato social os mecanismos necessários para que a leis da justiça sejam amplamente admitidas entre os homens.

Problemata: R. Intern. Fil. v. 8. n. 2 (2017), p. 117-137

ISSN 2236-8612 